\title{
ROOT CANAL DENTIN; THICKNESS OF HYBRID LAYER FORMATION. COMPARISON BY USING SELF- ETCH ADHESIVE AND CORONAL DENTIN (IN VITRO SCANNING ELECTRONIC MICROSCOPIC STUDY).
}

1. Lecturer

Operative Dentistry LUMHS

2. Associate Professor Operative Dentistry LUMHS

3. Research Officer Dentistry, LUMHS

4. Assistant Professor

Dentistry, LUMHS

Correspondence Address:

Dr. Salman Shams

Research Officer

Dentistry, LUMHS

salman_omfs@hotmail.com

Article received on:

23/08/2016

Accepted for publication: 20/10/2016

Received after proof reading: $18 / 01 / 2017$

\section{Dr. Mahwish Memon', Dr. Feroze Ali Kalhoro², Dr. Salman Shams ${ }^{3}$, Dr. Suneel Kumar ${ }^{4}$}

\begin{abstract}
Objectives: To compare the mean thickness of hybrid layer by using selfetch adhesive at coronal dentin and root canal dentin with scanning electronic microscope. Study Design: Experimental study. Setting: Liaquat University of Medical \& Health Sciences, Jamshoro. Period: July 2009 to $31^{\text {st }}$ December 2009. Material \& Methods: Fifty permanent single rooted extracted teeth were used in this study. The sample size was divided into two equal groups of 25 teeth each. Group $1(n=25)$ self etch adhesive was applied on coronal dentin then light cured for 10 seconds. Group $2(n=25)$ self etch adhesive to root canal dentin and then light cured was applied for 10 seconds then $2 \mathrm{~mm}$ thick layer was placed to adhesive bonded surfaces of coronal and root canal dentin. Data were analyzed using t-test of significance. $p$ Value was significant at $\leq 0.05$. Results: The mean \pm standard deviation of thickness of hybrid layer was $2.3088 \pm 1.027$ um in coronal dentin; and it was $2.1104 \pm 1.0316$ um in root canal dentin. Conclusion: There is no statistically significant differences in mean thickness of hybrid layer between root canal dentin and coronal dentin with self etch adhesive.
\end{abstract}

Key words: Dentin, Hybrid layer, Root canal dentin, Self-etch adhesive.

Article Citation: Memon M, Kalhoro FA, Shams S, Kumar S. Root canal dentin; Thickness of hybrid layer formation. Comparison by using self-etch adhesive root canal dentin and coronal dentin (in vitro scanning electronic microscopic study). Professional Med J 2017;24(1):166-170. DOI: 10.17957/TPMJ/17.3538

\section{INTRODUCTION}

The robustness of the adhesive dentin bond is related to the excellence of the hybrid layer that directly connects the bulk adhesive to the subadjacent, intact dentin. Usually, the adhesive monomers seats in all the space or gaps that lingers following removal of the mineral by acid etching technique and also envelop the open or exposed collagen fibrils. ${ }^{1}$

It is generally considered that dentine bonding agents get their bond strength by the creation of the so-called 'hybrid layer', originally described by Nakabayashi in $1982 .{ }^{2}$ He treated the dentine surface with an acidic primer, thus demineralizing the dentine surface to a depth of approximately 10 microns, prior to application of resin 4-methacryloyloxyethyltrimellitate anhydride (4META) bond.

"Smear layer" is formed by residual components on the surface when tooth is sliced by any bur or instruments and usually causing uniform coating of dentin and corks the entrance of the dentinal tubules, dentin permeability reduced. The porous and permeable smear layer of submicron channels usually allow the dentinal fluid to pass through this. ${ }^{3}$

The morphology of the smear layer is totally depend upon extent, instruments used and in which area of dentine it is formed. ${ }^{4}$

The existing adhesion strategy depends in which way it interact with smear layer in spite of many different classification of adhesive systems.

One strategy in which first etch and then rinse adhesives, which totally eradicate the smear layer plus superficial hydroxyapatite by etching with acid gel. The 2nd strategy is self-etch adhesives in which the smear layer permeable devoid of removing completely. ${ }^{5}$ 
The newly introduced self etching system allow simplification of restorative methods, reduced number of bottles in self etch adhesives results in time saving, reduction in post operative sensitivity also no need to apply acid etching before application. ${ }^{6}$

The less technique sensitive Self-etching primers generally; when compared with different other systems usually require a separate acid etching step and wet-bonding protocol.

Thickness of hybrid layer formation is $1-8 \mu \mathrm{m} .{ }^{7}$. According to some previous studies average thickness of hybrid layer in coronal dentin with self etch adhesive was $1.6 \mu \mathrm{m}(\mathrm{SD} 0.5)^{15}$ and in root canal dentin $1 \mu \mathrm{m}(\mathrm{SD} 0.9)^{8}$

The reliable bonding to dentine in coronal or root dentin is required in restorative technique.

This study will determine the difference of hybrid layer thickness at these two surfaces of tooth and this will provide clinical evidence for better bonding of dentin. So that it will be utilized where indicated in eligible cases.

\section{MATERIAL \& METHODS}

This experimental study carried out at "Liaquat University of Medical and Health Sciences, Jamshoro" from $3^{\text {rd }}$ July 2009 to $31^{\text {st }}$ December 2009. Fifty permanent single rooted non carious human teeth extracted for orthodontic reason were collected from Oral \& Maxillofacial Surgery department, teeth having loss of enamel and wear facets (abrasion, erosion and attrition) and teeth having caries were excluded and then selected teeth was stored in normal saline for 24hours. Selected teeth were section along the cementoenemal junction using diamond disc in a slow speed hand piece to separate into crown and root portions. Then Enamel was removed from crown area with tooth trimmer (dental laboratory Lathe Shangai China) to expose coronal dentin and the root will be ground longitudinally to expose root canal dentin. The samples were purposively divided in two groups of 25 teeth each. Group $1(n=25)=$ self etch adhesive. (Adper prompt L-Pop 3M ESPE) was applied to coronal dentin with applicator then adhesive was spreaded by a gentle stream of air pressure. Group $2(n=25)=$ self etch adhesive (Adper prompt L-Pop 3M ESPE) was applied to root canal dentin with applicator adhesive was spreaded by gentle stream of air pressure. All specimens were cured with halogen light (Caulk the $\max { }^{\mathrm{TM}}$ ) for 10 seconds. Then composite resin (Z250 3M ESPE)was added to adhesive bonded surfaces of coronal and root dentin in $2 \mathrm{~mm}$ thick layer and was light cured for minimum 40 seconds after that stored in water for next 24 hours then tooth specimen were cut in a cross section with diamond disc in a slow speed hand piece. The acid etch of phosphoric acid with $37 \%$ concentrated applied for only just 5seconds to make possible the observation of hybrid layer on the resin-dentin interface then specimens were coated with gold in JSD 1500 ion sputtering device Each specimen was examined under scanning electronic microscope (JEOL Model No. JSM6490LA, origin Japan) and photomicrographs of representative area was taken and examined (professor of operative dentistry) from cross section view to measure the thickness of hybrid layer. A tool of the scanning electronic microscope was used to measure the thickness of hybrid layer and the results were expressed in $\mu \mathrm{m}$. Data was analyzed using SPSS version 13.0. Thickness of hybrid layer was computed for all numerical variables.

\section{RESULTS}

In this study, thickness of hybrid layer was measured of 50 teeth 25 in coronal dentin 25 in root canal dentin. The age of study subjects ranged from 14 years to 18 years. The highest frequency of subjects was of 14 years $(n=8,32$ $\%$ ) whereas lowest frequency of subjects was of 18 years. The mean -+SD of age of the subjects included in this study was $15.56+1.42$ years (Table-I)

\begin{tabular}{|c|c|c|}
\hline Age & Frequency & Percentage \\
\hline 14 years & 16 & 32 \\
\hline 15 years & 10 & 20.0 \\
\hline 16 years & 10 & 20.0 \\
\hline 17 years & 08 & 16.0 \\
\hline 18 years & 06 & 12.0 \\
\hline \multicolumn{2}{|r|}{ Table-I. Age Distribution $(n=50)$} \\
Mean \pm SD age $=15.56 \pm 1.42$ years.
\end{tabular}


There was no statistically significant association of age with thickness of hybrid layer in coronal dentin and in root canal dentin. (Table-II)

\begin{tabular}{|c|c|c|c|}
\hline Age & $\begin{array}{l}\text { Coronal Dentin } \\
(\text { mean } \pm \text { SD } \mu \mathrm{m})\end{array}$ & $\begin{array}{l}\text { Root Canal Dentin } \\
(\text { mean } \pm \text { SD } \mu \mathrm{m})\end{array}$ & P-value \\
\hline 14 years & $1.9375 \pm 0.6183$ & $2.5225 \pm 01.3045$ & *0.309 \\
\hline 15 years & $1.9080 \pm 0.5865$ & $1.7960 \pm 0.8045$ & $\star 0.600$ \\
\hline 16 years & $3.2380 \pm 1.7526$ & $1.7660 \pm 0.5579$ & *0.096 \\
\hline 17 years & $1.9700 \pm 0.1617$ & $1.8375 \pm 0.3497$ & *0.578 \\
\hline 18 years & $2.8700 \pm 0.7101$ & $2.4733 \pm 01.7732$ & *0.584 \\
\hline \multicolumn{4}{|c|}{$\begin{array}{l}\text { Table-II. Association of Age with Thickness of Hybrid } \\
\qquad \begin{array}{l}\text { Layer }(n=25) \text {. } \\
\text { * non-significant. }\end{array}\end{array}$} \\
\hline
\end{tabular}

Statistically analysis of the thickness of hybrid layer revealed that there is no statistically significant difference between the mean thickness of hybrid layer measurements in coronal dentin and root canal dentin. $(p=0.46)$. The mean \pm standard deviation of thickness of hybrid layer was 2.3088 \pm 1.027 um in coronal dentin; and it was 2.1104 \pm 1.0316 um in root canal dentin (Table-III).

\begin{tabular}{|l|c|c|}
\hline \multicolumn{1}{|c|}{ Study Group } & $\begin{array}{c}\text { Mean } \pm \text { SD } \\
\text { Thickness }(\boldsymbol{\mu m})\end{array}$ & P-value \\
\hline Coronal Dentin & $2.3088 \pm 1.0217$ & \multirow{2}{*}{$0.46^{*}$} \\
\hline Root Canal Dentin & $2.1104 \pm 01.0316$ & \\
\hline \multicolumn{2}{|c|}{ Table-III. Comparison of Hybrid Layer Thickness } \\
between Study Groups $(\mathrm{n}=25)$. \\
* non-significant.
\end{tabular}

It was revealed by both methods that majority of study population presented with hybrid layer thickness of up to $2.00 \mathrm{um}$. There was some difference of frequencies when distributed among thickness groups for both procedures, though not statistically significant $(p=.174)$ as detailed in (Table-IV).

\begin{tabular}{|c|c|c|}
\hline $\begin{array}{c}\text { Hybrid Layer } \\
\text { Thickness }\end{array}$ & $\begin{array}{c}\text { Coronal Dentin } \\
\text { Frequency (\%) }\end{array}$ & $\begin{array}{c}\text { Root Canal Dentin } \\
\text { Frequency (\%) }\end{array}$ \\
\hline $1.0-2.0 \mu \mathrm{m}$ & $11(44)$ & $16(64)$ \\
\hline $2.1-3.0 \mu \mathrm{m}$ & $10(40)$ & $05(20)$ \\
\hline $31 .-4.0 \mu \mathrm{m}$ & $03(12)$ & $01(04)$ \\
\hline $4.1-5.0 \mu \mathrm{m}$ & $00(00)$ & $03(12)$ \\
\hline$>5.0 \mu \mathrm{m}$ & $01(04)$ & $00(00)$ \\
\hline \multicolumn{2}{|c|}{ Table-IV. Frequency of Study Groups $(\mathrm{n}=25)$} \\
\hline
\end{tabular}

\section{T-Test}

\begin{tabular}{|l|l|c|c|c|c|c|}
\hline \multirow{2}{*}{ Pair 1 } & Mean & N & Std. Deviation & Std. Error Mean & P-value \\
\hline & Root Canal Dentin & 2.3088 & 25 & 1.02170 & .20434 & 0.460 \\
\hline & 2.1104 & 25 & 1.03158 & .20632 & \\
\hline
\end{tabular}

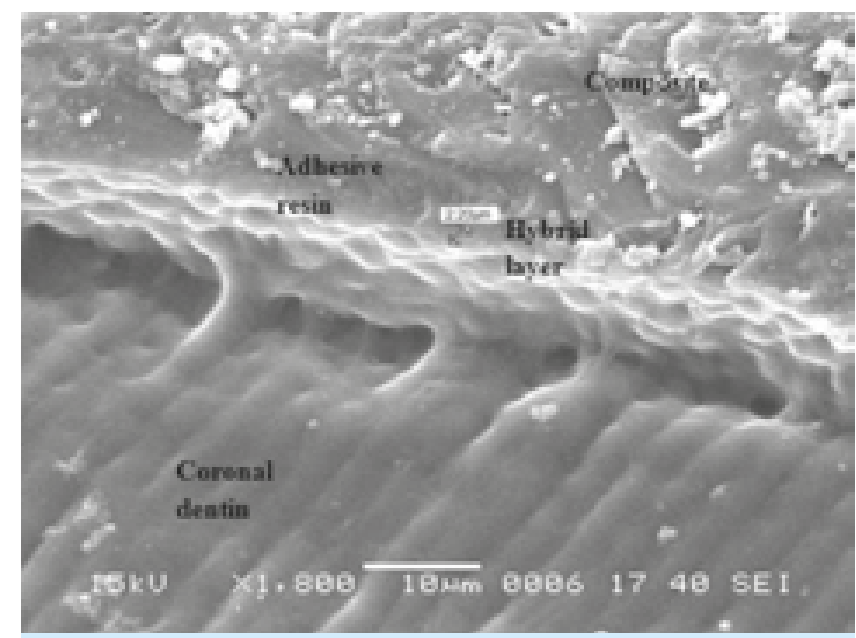

Figure-1. Scanning electronic microscopic image of coronal dentin showing thickness of hybrid layer i.e. 2.20 $\mu \mathrm{m}$.

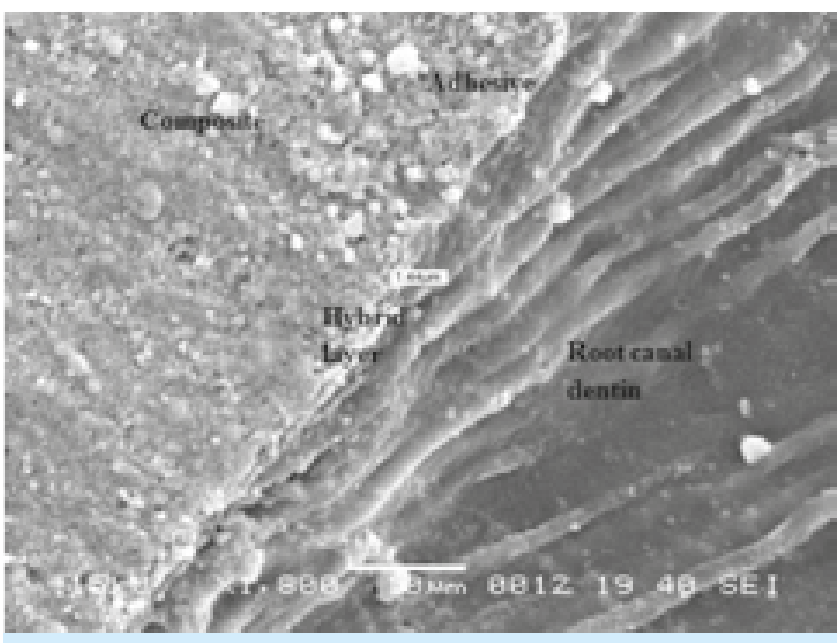

Figure-2. Scanning microscopic image of root canal dentin showing continuous hybrid layer having thickness of $1.44 \mu \mathrm{m}$. 


\section{DISCUSSION}

In the current study the average thickness of hybrid layer at coronal dentin is $2.3 \mu \mathrm{m}$ in contrast with this study comparable results could be revealed for the hybrid layer thickness in a scanning electronic microscopic research of pioch et $\mathrm{al}^{9}$ the mean thickness of the hybrid layer was $1.89 \mu \mathrm{m}$ and $2.34 \mu \mathrm{m}$. Sundfeld R.H et $\mathrm{al}^{6}$ in his study told that use of self etching adhesive Adper prompt L-Pop on the intact dentin tissue illustrated that this insistent self-etching was capable of demineralizing the subsurface dentin with a same capability of formation of an authentic hybrid layer that was approximately 3.13 and $3.72 \mu \mathrm{m}$. In comparison to the results of this study (bitter et al 2004) ${ }^{10}$ stated the average thickness of the hybrid layer with self etching adhesive at root canal dentin were 0.41 and $0.85 \mu \mathrm{m}$ respectively.

According to Foxton R.M et $\mathrm{al}^{11}$ thickness of hybrid layer obtained was $1 \mu \mathrm{m}$ or less but the effective bonding was attained to the dentin of root canal. The single-step self etch adhesive applied in his experiment was uni fill self etching bond, that includes the adhesive monomer, 4-methacryloxyethlyl bimellitic acid(4-MET) and has a $\mathrm{pH}$ of 2.0 which is less acidic than the bonding agent used in present study this may be the reason for thin hybrid layer formation. However in the present experiment thickness of hybrid layer obtained was $2.1 \mu \mathrm{m}$.

De Goes et $\mathrm{al}^{12}$ evaluated micro tensile bond potency among crown dentin and root canal dentin with double adhesive systems in their study they found the adhesive used to coronal dentin illustrated considerably greater bond strength standards than those determined for root canal dentin bonds.

\section{CONCLUSION}

Thickness of hybrid layer has no statistically significant difference between root canal dentin and crown dentin when it was bonded with self etch adhesive.

However the bond of adhesive is almost same at root canal dentin and coronal dentin but to see the real effectiveness and longevity of their bonding to tooth tissue should be investigated to understand the clinical behavior.

Copyright (C) 20 Oct, 2016.

\section{REFERNCES}

1. Wang Y, Spencer P. Hybridization efficiency of the adhesive/dentin interface with wet bonding. Dent Res. 2003;82(2):141-5

2. Nakabayshi N, Kojima K, Masuhura E: The promotion of adhesion by the infiltration of monomers into tooth substrate. J Biomed Mater Res 1982; 16:265-73.

3. Pashley $\mathrm{DH}$, The effect of acid etching on the pulpodentin complex. Oper Dent. 1992; 17:229-42.

4. Eick JD, Cobb CM, Chapell RP. The dentinal surface: its influence on dentinal adhesion. part I. Quint Int. 1991;22:967-7.

5. Jorge Perdigao. New Developments in Dental Adhesion. Dent Clin N Am. 2007; 51:333-357.

6. Renato HS, Thiago AV, Rodrigo SA, Andre LF. Hybrid layer thickness and resin tag length of a self etching adhesive bonded to sound dentin. J Dent. 2005; 33:675-8.

7. Ding P, Paul GF, Diana W, Thomas P, Bettina D. Relationship between microtensile bond strength and nanoleakage at the composite dentin interface. Dent Mater J. 2009; 25:135-41.

8. Foxton RM, Nakajima M, Tagami J. Adhesion to root canal dentin using one and two-step adhesives with dual cure composite core materials. J Oral Rehabil. 2005; 32:97-104.

9. Pioch $\mathrm{T}$, Stotz $\mathrm{S}$, Duschner $\mathrm{H}$. Influence of different etching times on hybrid layer formation and tensile bond strength. Am J Dent. 2006; 11:202-6.

10. Kerstin B. A confocal laser SEM investigation of different dental adhesives bonded to root canal dentin. Int Endod J 2004; 37:840-8.

11. Foxton RM, Nakajima M, Tagami J, Miura H. Adhesion to root canal dentine using one and two-step adhesives with dual-cure composite core materials. $\mathrm{J}$ Oral Rehabil. 2005; 32:97-104.

12. Mario F.D, Marcelo G, Richard M,Toru N. Microtensile bond strength between crown and root dentin and two adhesive systems. J Prostht Dent. 2007; 97:223-8. 


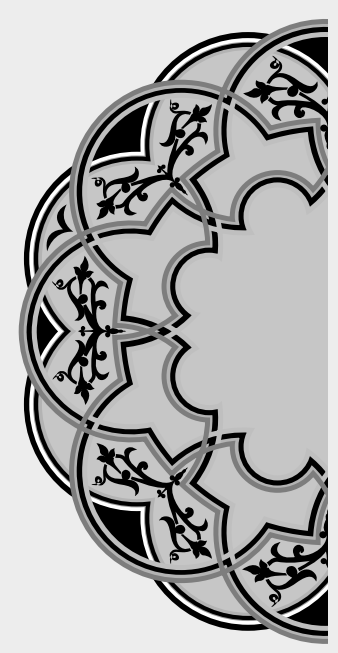

\title{
"Impossible is not a face, it's an opinion."
}

\author{
Unknown
}

\section{AUTHORSHIP AND CONTRIBUTION DECLARATION}

\begin{tabular}{|c|c|c|c|}
\hline Sr. \# & Author-s Full Name & Contribution to the paper & Author $=$ s Signature \\
\hline 1 & Mahwish Memon & $\begin{array}{l}\text { Study conception and } \\
\text { design acquisition of data } \\
\text { Drafting of manuscript }\end{array}$ & 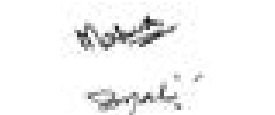 \\
\hline 2 & Dr. Feroze Ali Kalhoro & $\begin{array}{l}\text { Acquisition of data, Final } \\
\text { approval }\end{array}$ & \\
\hline 3 & Dr. Salman Shams & $\begin{array}{l}\text { Analysis and intrepation of } \\
\text { data }\end{array}$ & \\
\hline 4 & Dr. Suneel Kumar & $\begin{array}{l}\text { Plagiarism check Analysis } \\
\text { and interpretation of data1 }\end{array}$ & \\
\hline
\end{tabular}

